\title{
Healthy Gut, Healthy Brain!
}

\section{Ayonika Mukherjee*}

Department, N/A, University/Organization, United States of America

*Corresponding Author: Ayonika Mukherjee, Department, N/A, University/

Organization, United States of America.
Received: March 02, 2020

Published: March 20, 2020

C All rights are reserved by Ayonika

Mukherjee.
Microorganisms have been in existence from prehistoric times and they are present everywhere land, air, water, on living and non-living organisms and even in our guts. There are trillions of microorganisms that are inhabiting in human digestive tracts and intestine and are referred to as gut microbiota or gut microbes. The gut microbiota is a multifaceted ecological community which contributes to different body regulation like metabolic and immune responses. Literature has shown an association between gut microbe dysbiosis and inflammatory diseases. Over the last few years, a lot of research has been done to understand the gut microbiota better and modes to maintain a healthy gut microbiota and how they can be used to reverse some of these gut inflammation diseases. One of the most major findings has been the gut-brain axis, where researchers have shown a link between the gut microbiota and the central nervous system.

The communication between neural systems and the gut is bidirectional, and the gut microbiota influences neural ailments like depression, stress, anxiety attacks, and pain modulations. There are over 100 billion neurons present in a human brain, astonishingly there are also around 500 million neurons present in the gut and they are connected by the vagus nerve, which is responsible for the connection between the gut and the brain. Studies have shown that gastrointestinal diseases are caused by vagus nerve as a symptom of stress and anxiety. Studies have also shown a decrease in vagus nerve function in patients with gastrointestinal diseases like irritable bowel syndrome (IBS).

There have been studies that show that patients with neurodegenerative diseases have altered gut microbiota composition (gut dysbiosis). Gut dysbiosis induces disruption in the permeability of the intestinal barrier and results in immune activation which leads to a systemic inflammatory response. The barrier disruption causes the circulation of proinflammatory cytokine in the blood circulation which in turn may impair the blood-brain barrier and cause brain inflammation and lead to neurodegeneration.

In the bottom line gut microbiota is very important in maintaining health and immune response, so keeping a healthy gut microbe is very important. By changing the types of bacteria in your gut, it may be possible to improve your brain health.

\section{Assets from publication with us}

- Prompt Acknowledgement after receiving the article

- Thorough Double blinded peer review

- Rapid Publication

- Issue of Publication Certificate

- High visibility of your Published work

Website: www.actascientific.com/

Submit Article: www.actascientific.com/submission.php Email us: editor@actascientific.com

Contact us: +919182824667 